\title{
SEPARATION AND PURIFICATION OF ENTEROTOXINS FROM A STRAIN ESCHERICHIA COLI PATHOGENIC FOR PIGS
}

\author{
I. De G. Mitchell, M. J. TAMe, AND R. Kenworthy \\ Unilever Research Ltd, Colworth House, Sharnbrook, Bedfordshire MK44 ILQ
}

INVESTIGATIONS on the pathogenic role of Escherichia coli enterotoxin (Kohler, 1968, 1971 a; Smith and Gyles, 1970b; Kohler and Cross, 1971) and mode of action (Al-Awqati, Wallace and Greenough, 1972; Evans et al., 1972) have been performed with very impure material (Jacks et al., 1973). Enterotoxins that are more accurately defined and of greater purity are needed so that (1) results obtained by workers in different laboratories can be properly compared (2) the importance of enterotoxin in scouring can be further elucidated, and (3) the development of a method of assay more reliable than that made in ligated segments of intestine may be facilitated.

Attempts to concentrate and purify enterotoxins produced in culture supernates by pathogenic $E$. coli have given contradictory results (Kohler, 1968, 1971b; Smith and Gyles, 1970a; Larivière, 1971; Bywater, 1972; Jacks et al., 1973). This may be because different enterotoxins are produced by different strains (Truszczynski and Ciosek, 1972) or because a single strain may produce enterotoxins with a variety of molecular weights; a further possibility is that the method of culture influences which of the various enterotoxic components predominates.

We have examined, by ultrafiltration and column chromatography, enterotoxins produced by pathogenic E. coli in defined medium (Mitchell, Tame and Kenworthy, 1974) thereby avoiding some of the complexities introduced by media containing much ultraviolet-absorbent material.

\section{Materials AND Methods}

Bacterial strain. E. coli strain P16 (serotype O9; K9) was obtained from Dr H. W. Smith.

Defined medium and culture technique. These have been described previously (Mitchell et al., 1974).

Assay method for enterotoxin. The ligated intestinal-segment method (De and Chatterje, 1953; Moon, Sorensen and Sautter, 1966; Smith and Gyles, 1970b) was used as by Mitchell et al. (1974).

Concentration methods. Enterotoxic supernates were prepared from defined-medium cultures of $E$. coli by centrifugation for $20 \mathrm{~min}$. at $75,000 \mathrm{~g}$. These prepations were then either $(a)$ freeze-dried and redissolved in distilled water to give 10- to 25 -fold concentration, or $(b)$ reverse-dialysed against $30 \% \mathrm{w} / \mathrm{v}$ polyethylene glycol for 24 hours to give between 7 and 15-fold concentration; the cellulose membrane used had a molecular-weight exclusion of between $10^{4}$ and $2 \times 10^{4}$ daltons.

Received 16 Jan. 1974; accepted 25 Feb. 1974.

J. MED. MICROBIOL. -VOL. 7 (1974)

439 
Ultrafiltration. Diaflo apparatus was used at $138-276 \mathrm{kN}$ per $\mathrm{m}^{2}$ with XM.100, PM.30, PM.10 or UM.2 membranes having, respectively, molecular-weight exclusion values of $10^{5}, 3 \times 10^{4}, 10^{4}$ and $10^{3}$. Freeze-dried concentrates were too viscous for ultrafiltration, and ultrafiltrations of reverse-dialysed material was inconveniently slow; most of the studies were therefore performed directly on broth supernates.

In an enterotoxic broth, the proportion of the total enterotoxic activity caused by the unfilterable toxins and the proportion due to the filterable toxins could be calculated from the filtration data by means of formulae derived as follows: let $T=$ enterotoxic activity per $\mathrm{ml}$ in the filtrate; $X=$ activity per $\mathrm{ml}$ in the retentate; $A=$ activity per $\mathrm{ml}$ due to unfilterable toxin; $a=$ activity per $\mathrm{ml}$ due to filterable toxin; $v=$ volume of retentate in $\mathrm{ml} ; V=$ total volume in $\mathrm{ml} ; \boldsymbol{P}=$ activity per $\mathrm{ml}$ due to unfilterable toxin if the retentate was reconstituted to the original volume $\mathrm{V} ; H=$ the percentage of unfilterable toxin before filtration; $L=$ the percentage of lower molecular weight (MW) filterable toxin before filtration. If it is assumed that any loss of activity occurs equally in the filterable and unfilterable toxin and that there is complete separation, then

$$
\begin{gathered}
a=T(\text { no } A \text { passes through the filter) } \\
X=A+a \text { (by definition) } \\
\therefore A=X-a
\end{gathered}
$$

Substituting for $a$ from (1) in (2)

$$
A=X-T
$$

$$
\text { and } P=A \frac{v}{V} \text { (by definition) }
$$

Substituting $A$ from (3) in (4)

$$
\begin{gathered}
P=(X-T) \frac{v}{V} \\
\text { and } H=\frac{P}{P+a} \times 100 \text { (by definition) }
\end{gathered}
$$

Substituting $P$ and $a$ in (6) from equations (5) and (1)

$$
\begin{aligned}
H & =\frac{(X-T) \frac{v}{V}}{(X-T) \frac{v}{V}+T} \times 100 \\
\text { and } L & =100-H \text { (by definition) }
\end{aligned}
$$

Separation of enterotoxins on Sepharose and Sephadex. Concentrates were applied in volumes of 10 to $20 \mathrm{ml}$ to columns of Sepharose 4B, Sephadex G50 or Sephadex G10. Eluants consisted of $0.85 \% \mathrm{NaCl}$ adjusted to $p \mathrm{H} 7.4$ by the addition of alkali, or phosphate buffer $(p \mathrm{H} \mathrm{7})$ made up of $0.7 \% \mathrm{~K}_{2} \mathrm{HPO}_{4}$ and $0.3 \% \mathrm{NaH}_{2} \mathrm{PO}_{4}$. The following substances were used for the preparation of standard curves for MW calculations: 12 crystals of dextran blue, MW $2 \times 10^{7}$, used to find the void volume; $10 \mathrm{ml}$ impure porcine IgM, MW $9 \times 10^{5} ; 50 \mathrm{mg}$ dextran sulphate, MW $5 \times 10^{5} ; 50 \mathrm{mg}$ porcine IgG, MW $1.5 \times 10^{5} ; 25 \mathrm{mg}$ lysozyme, MW 1.44 $\times 10^{4} ; 4 \mathrm{ml}$ standard (40 units per ml) insulin, MW 5.8 $\times 10^{3} ; 50 \mathrm{mg}$ streptomycin sulphate, MW 1358, assuming monodissociation; 25 mg ATP, MW 623; 0.5 $\mathrm{mg}$ tetracycline, MW 444; 0.5 mg riboflavin, MW 376; $25 \mathrm{mg}$ adenosine, MW 267;12.5 mg 2-amino-purine, MW198; 12.5 mg 5-bromo-uracil, MW 191; $12.5 \mathrm{mg}$ adenine, MW 135. The IgM and IgG samples were obtained from Dr P. Porter, of this laboratory, and the rest were commercially available. Fractions were collected in $4.75-$ or $9.5-\mathrm{ml}$ portions and the effluent from the columns was continuously monitored for ultraviolet-light transmission at $280 \mathrm{~nm}$. All the standard substances absorbed in the ultraviolet region except streptomycin, which was assayed by measurement of the zone of inhibition on a lawn of sensitive $E$. coli 
strain G1253 (O147; K89; K88ac; H19). The streptomycin could not be used with phosphate buffer. Enterotoxic activity was assayed by the ligated-intestine method. For comparative purposes, all results are expressed in KAV units, defined as follows:

$$
\mathrm{KAV}=\frac{\text { elution volume-void volume }}{\text { bed volume-void volume }}
$$

Standard curves for MW determinations were drawn by plotting KAV against the reciprocal of the MW.

\section{RESULTS}

\section{Concentration of enterotoxin}

Initial attempts at concentration by means of solvent and salt precipitations were unsuccessful, giving at best less than $10 \%$ recovery of enterotoxic activity.

TABLE I

Ultrafiltration of enterotoxic culture supernates from Escherichia coli strain P16

\begin{tabular}{|c|c|c|c|c|c|c|c|}
\hline $\begin{array}{l}\text { Starting } \\
\text { material }\end{array}$ & $\begin{array}{l}\text { Number of } \\
\text { separate } \\
\text { filtrations }\end{array}$ & $\begin{array}{l}\text { Filter } \\
\text { used }\end{array}$ & $\begin{array}{c}\text { Fraction } \\
\text { tested }\end{array}$ & $\begin{array}{l}\text { Volume } \\
\text { reduction }\end{array}$ & $\begin{array}{l}\text { Degree of } \\
\text { concentration } \\
\text { of activity* }\end{array}$ & $\begin{array}{l}\text { Percentage of } \\
\text { unfilterable } \\
\text { activity }\end{array}$ & $\begin{array}{c}\text { Percentage of } \\
\text { activity } \\
\text { lost in } \\
\text { filtration }\end{array}$ \\
\hline cs & 1 & XM.100 & $\begin{array}{l}\text { Retentate } \\
\text { Filtrate }\end{array}$ & $\begin{array}{l}\times 10 \\
\times 1\end{array}$ & $\left.\begin{array}{l}\times 3.5 \\
\times 1.0\end{array}\right\}$ & 20 & 0 \\
\hline CS & 3 & PM.30 & $\begin{array}{l}\text { Retentate } \\
\text { Filtrate }\end{array}$ & $\begin{array}{l}\times 15 \\
\times 1\end{array}$ & $\left.\begin{array}{l}\times 2.8 \\
\times 0.8\end{array}\right\}$ & 14 & 7 \\
\hline $\mathrm{CS}$ & 2 & PM.10 & $\begin{array}{l}\text { Retentate } \\
\text { Filtrate }\end{array}$ & $\begin{array}{l}\times 8 \\
\times 1\end{array}$ & $\left.\begin{array}{r}\times 2.9 \\
\times 0.4\end{array}\right\}$ & 44 & 29 \\
\hline $\begin{array}{l}\text { PM.30 filtrate } \\
\text { of CS }\end{array}$ & 2 & UM.2 & $\begin{array}{l}\text { Retentate } \\
\text { Filtrate }\end{array}$ & $\begin{array}{l}\times 12 \\
\times 1\end{array}$ & $\left.\begin{array}{r}\times 4.3 \\
\times 0.4\end{array}\right\}$ & 45 & 27 \\
\hline
\end{tabular}

* Derived from ligated-loop assay.

$\dagger$ Calculated by equation (7) derived under Materials and methods.

Reverse-dialysis gave about $50 \%$ recovery whilst freeze-drying gave 80 to $100 \%$. Unfortunately the viscosity of freeze-dried concentrates rendered them difficult to apply to columns and almost impossible to ultrafilter.

\section{Ultrafiltration}

The slime in culture supernates tended to block ultrafilters as filtration progressed. Thus the time taken for the procedure became excessively long, either where the material was fairly concentrated or where filters with small pore size were used. The data in table I indicate that activity tended to be lost in filtrations of long duration.

The data in tables I and II show that the enterotoxic activity in the supernates of strain P16 could be split into four fractions according to $\mathrm{MW}$, as follows: $>10^{5}, 3 \times 10^{4}-10^{4}, 10^{4}-10^{3},<10^{3}$.

$X M .100$ fltration. This indicated that 14 to $20 \%$ of the enterotoxic activity was associated with MW values exceeding $10^{5}$.

PM.30 filtration. An insignificant amount of the activity that passed through an XM.100 filter was retained by a PM.30 filter (table II) showing that no significant activity was associated with MW values in the range $10^{5}$ to $3 \times 10^{4}$. 
PM.10 filtration. The results in table I suggest that $44 \%$ of the activity of the enterotoxic supernates was contained in fractions having a MW exceeding 104. The data obtained with XM.100 and PM.30 membranes showed that $14-20 \%$ of the total toxin had a MW exceeding $3 \times 10^{4}$; therefore $24-30 \%$ must have had a MW between $3 \times 10^{4}$ and $10^{4}$.

UM.2 filtration. Because of their slime content, it was impracticable to filter the enterotoxin culture supernates directly through a UM.2 membrane. Therefore, all UM.2 filtrations were performed on PM.30 filtrates, which lacked $14-20 \%$ of the total activity (tables I and II). From the data in table I, it can be calculated that about $44-47 \%$ of the total enterotoxic activity was associated with a MW of less than $10^{3}$, and $33-42 \%$ with a MW of more than $10^{3}$ but less

TABLE II

Sequential ultrafiltration of enterotoxic concentrate prepared by reverse dialysis of culture supernates of E. coli strain P16

\begin{tabular}{|c|c|c|c|c|}
\hline $\begin{array}{l}\text { Filter } \\
\text { used }\end{array}$ & $\begin{array}{c}\text { Fraction } \\
\text { tested }\end{array}$ & $\begin{array}{l}\text { Volume } \\
\text { reduction }\end{array}$ & $\begin{array}{l}\text { Degree of } \\
\text { concentration } \\
\text { of activity* }\end{array}$ & $\begin{array}{l}\text { Percentage of } \\
\text { unfilterable } \\
\text { activity† }\end{array}$ \\
\hline XM.100 & $\begin{array}{l}\text { Retentate } \\
\text { Filtrate }\end{array}$ & $\begin{array}{l}\times 10 \\
\times 1\end{array}$ & $\left.\begin{array}{l}\times 2.4 \\
\times 0.9\end{array}\right\}$ & 14 \\
\hline PM.30 & $\begin{array}{l}\text { Retentate } \\
\text { Filtrate }\end{array}$ & $\begin{array}{r}\times 10 \\
\times 1\end{array}$ & $\left.\begin{array}{l}\times 1.1 \\
\times 0.9\end{array}\right\}$ & 2 \\
\hline UM.2 & $\begin{array}{l}\text { Retentate } \\
\text { Filtrate }\end{array}$ & $\begin{array}{rr}\times 6 \\
\times 1\end{array}$ & $\left.\begin{array}{r}\times 3.4 \\
\times 1.2\end{array}\right\}$ & 24 \\
\hline
\end{tabular}

Footnotes as in table I.

No activity was lost in filtration.

than $3 \times 10^{4}$. As already indicated, $24-30 \%$ had a MW between $3 \times 10^{4}$ and $10^{4}$; therefore $3-18 \%$ of the total activity was associated with $\mathrm{MW}$ values in the range 104-103.

Comparison of the data for UM.2 filtrations in tables I and II shows that a much higher percentage of low-MW toxin was obtained after sequential filtration. This contradicts the theoretical expectation, because the toxin used in sequential filtrations was first concentrated by reverse dialysis and should have lost much of the material of MW less than 103. This apparent anomaly can best be explained by assuming that one or more of the higher MW toxins fragmented during filtration.

\section{Gel-filtration}

The standard curves for MW calculation are shown in fig. 1.

High-MW toxin $\left(>10^{5}\right)$. Because the 25 -fold concentrate produced by freeze-drying was very slimy and viscous, the ultraviolet absorption peak, obtained from Sepharose-4B gel filtration, was retarded and excessively broad (fig. 2a). However, when the fractions responsible for this peak were reconcentrated 10-fold by reverse dialysis and run again on Sepharose 4B (fig. 2b) 
a much sharper peak was obtained. Of the total activity added to the column in the first run (fig. $2 a$ ) $17 \%$ was recovered between KAV 0.2 and 0.7 in the

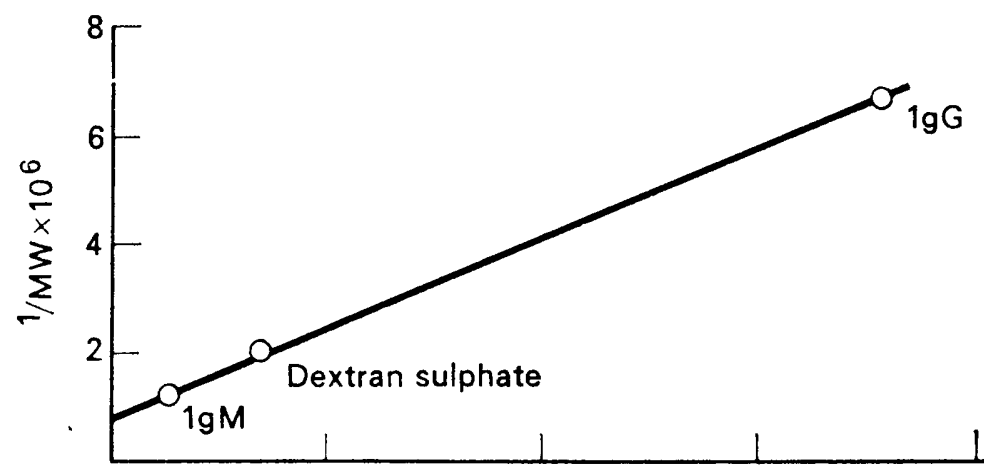

(a)

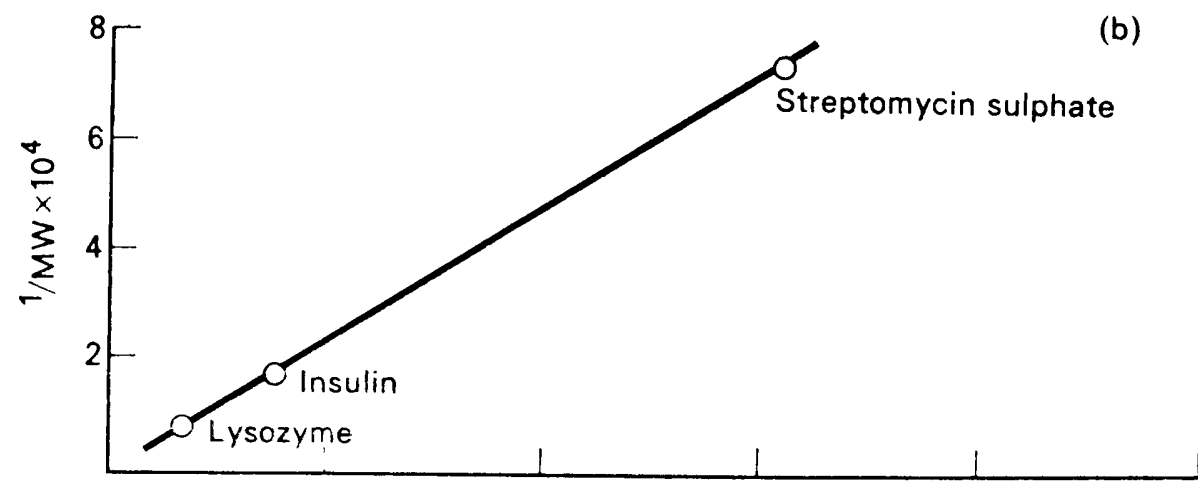

(c)

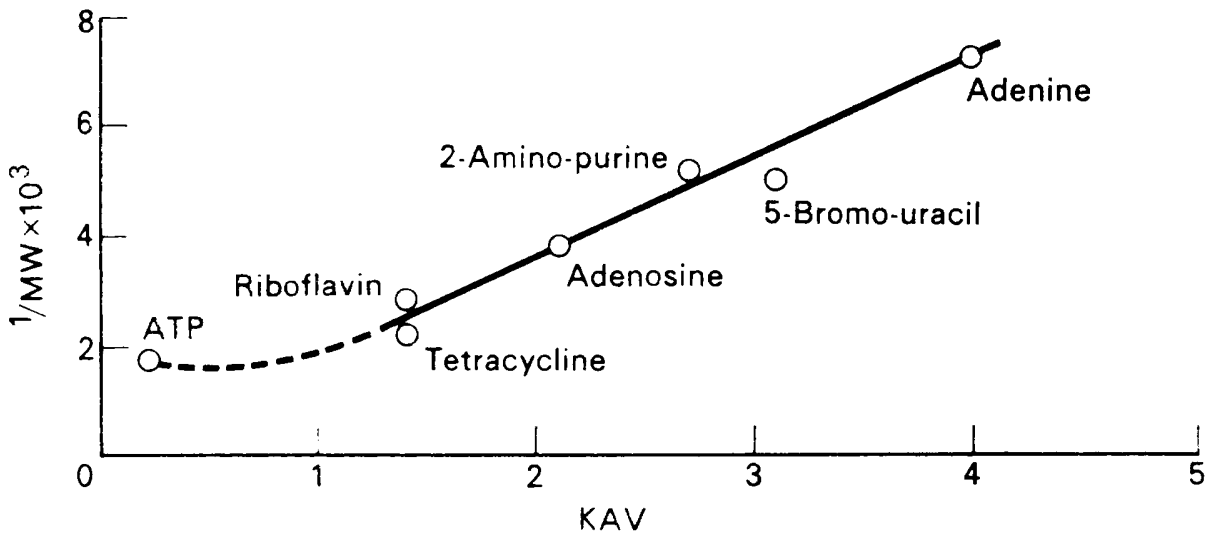

FIG. 1.-Standard curves for determining MW values from gel-filtration results. The curves were obtained with (a) Sepharose 4B, (b) Sephadex G50, and (c) Sephadex G10.

second run (fig. $2 b$ ), i.e., it lay between MW $5.2 \times 10^{5}$ and $9.9 \times 10^{5}$ as calculated from the standard curve (fig. $1 a$ ). If the apex of the ultraviolet absorption peak were coincident with maximum enterotoxic activity, the MW would be $5.9 \times 10^{5}$. 


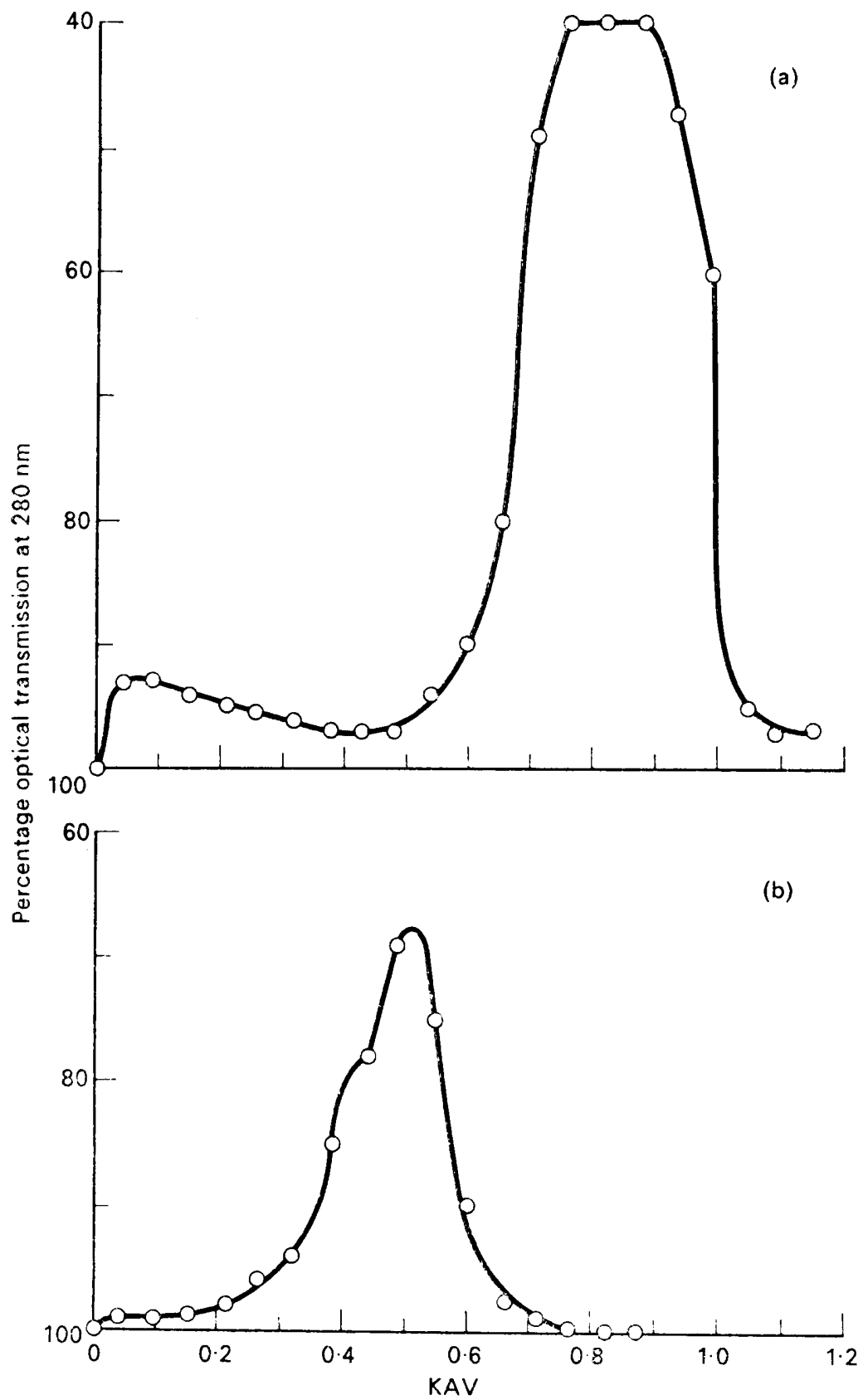

Fig. 2.-Separation of high-MW enterotoxin on Sepharose 4B. The column measured $48 \times 3.5 \mathrm{~cm}$ and the eluant was saline. (a) The toxin consisted of $15 \mathrm{ml}$ of a 25 -fold concentrate prepared by freeze-drying. (b) The toxin consisted of $22 \mathrm{ml}$ of a 10-fold concentrate prepared by reverse dialysis of fractions between KAV 0.5 and 1.1 from the run shown in $(a)$. 
Medium-MW toxin $\left(3 \times 10^{4}-10^{3}\right)$. This was separated on Sephadex G50 with either $0.85 \% \mathrm{NaCl}$ or phosphate-buffer eluant. When a $0.1 \% \mathrm{NaCl}$

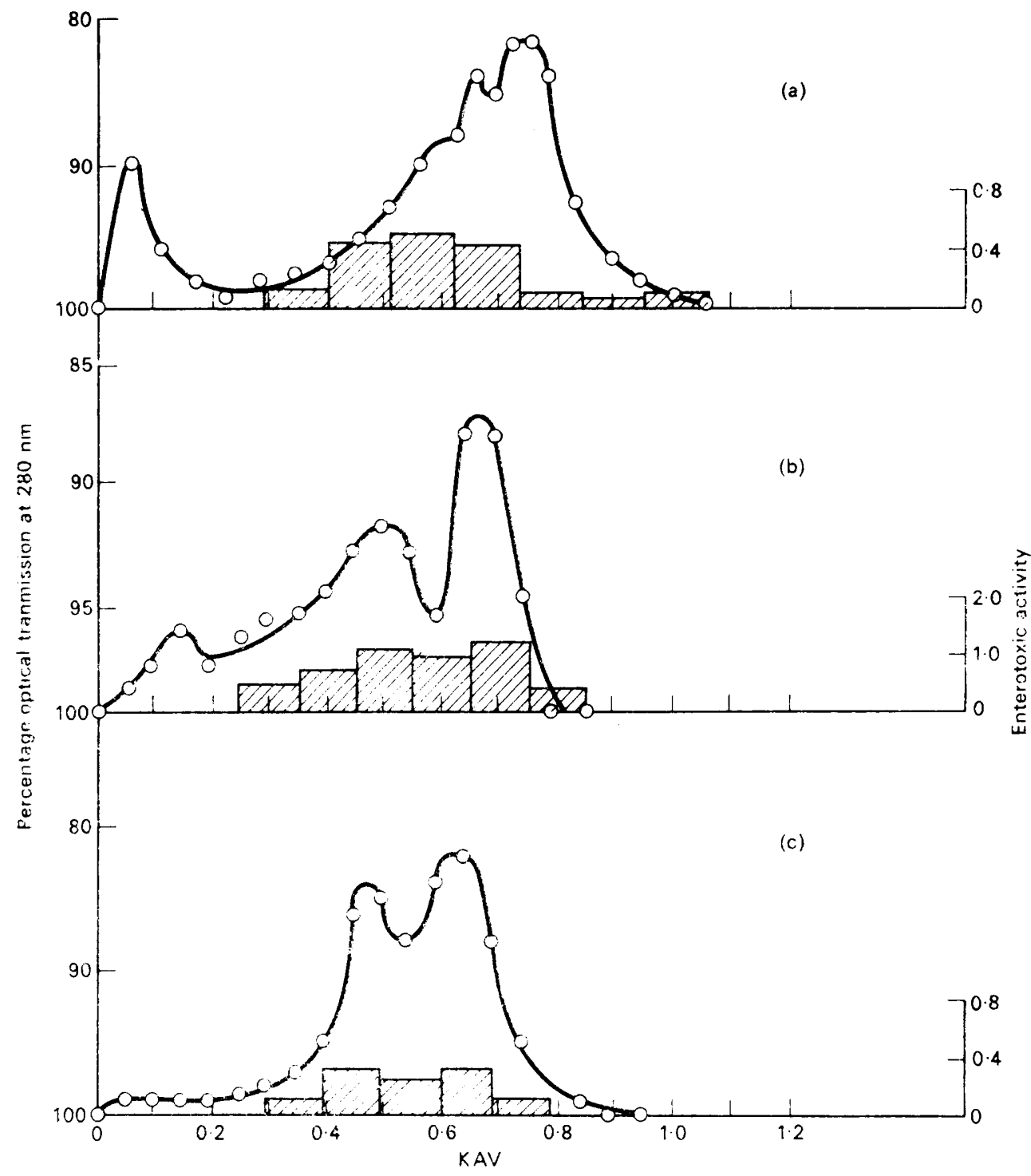

FIG. 3.-Separation of medium-MW enterotoxin on Sephadex G50. $\bigcirc-\bigcirc=$ Ultraviolet transmission. Enterotoxic activity. (a) The column measured $90 \times 3.5 \mathrm{~cm}$ and the eluant was phosphate buffer. The toxin consisted of $20 \mathrm{ml}$ of a 15 -fold concentrate prepared by freezedrying the exclusion fractions from a G10 column. (b) The column measured $52 \times 3.5 \mathrm{~cm}$ and the eluant was saline. The toxin consisted of $15 \mathrm{ml}$ of an XM. 100-membrane filtrate from a 10-fold concentrate prepared by reverse dialysis. (c) The column and eluant were as in $(b)$, and the toxin consisted of $20 \mathrm{ml}$ of a PM. 30 -membrane filtrate from a 10 -fold concentrate prepared by reverse dialysis.

eluant was used the peaks spread and little activity was recovered, indicating instability in eluants of low ionic strength. 
The results (fig. 3) show that the medium-MW toxins were found between KAV 0.3 and 0.8 i.e., between MW $1.7 \times 10^{4}$ and $5.6 \times 10^{3}$ (fig. 1). If a line of closest fit were drawn through the histograms in figs. $3 b$ and $3 c$ there would be a double peak of enterotoxic activity exactly coinciding with the peaks of ultraviolet absorbence. This strongly suggests that the ultraviolet absorbence was at least partly measuring enterotoxin and indicates that there were two toxins, one of MW $9.5 \times 10^{3}$ and the other of MW 6.7 $\times 10^{3}$. It is interesting that the second peak of ultraviolet absorbence was lost on UM.2 filtration (fig. 4) whilst the first peak remained stable.

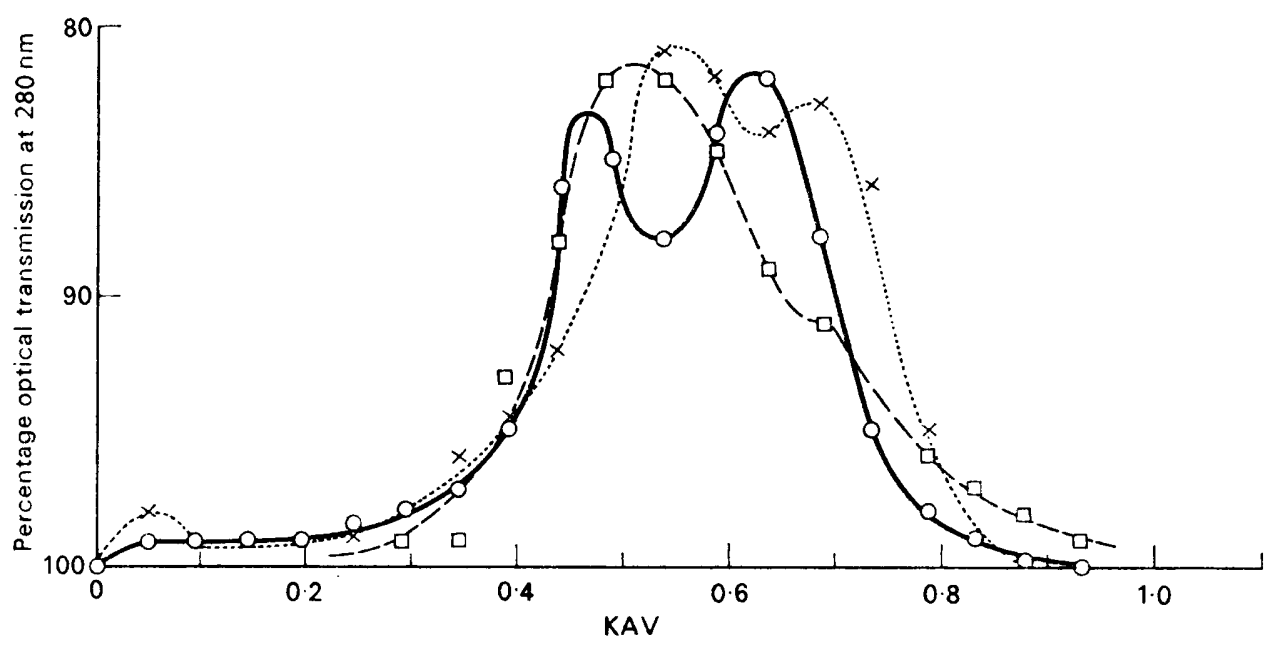

Fig. 4.-Gel filtration of UM.2-membrane retentate on Sephadex G50. The column measured $52 \times 3.5 \mathrm{~cm}$ and the eluant was saline. Toxin, concentrated 10 -fold by reverse dialysis, was filtered through a PM.30 membrane. The filtrate was used as follows: $O-O=20 \mathrm{ml}$ unconcentrated filtrate; $\times \cdots . \cdots \times=20 \mathrm{ml}$ filtrate, concentrated 2.5 times by UM. 2 filtration; $\square-\cdots \square=12 \cdot 5 \mathrm{ml}$ filtrate, concentrated 6 times by UM.2 filtration.

All the enterotoxic activity in each reverse-dialysed ultrafiltered preparation applied to the G50 Sephadex columns was recovered between KAV 0.3 and 0.8 whereas only $60 \%$ of the total activity in a freeze-dried preparation was recovered in this region.

Low- $M W$ toxin $\left(>10^{3}\right)$. To avoid loss of low-MW material, freeze-dried concentrates were applied directly to a G10 column. Because preliminary ultrafiltration was impracticable we tried, with only partial success, to remove some of the slime and residue by centrifugation for 1 hour at $75,000 \mathrm{~g}$. Even so the exclusion peak spread further than was desirable (fig. 5). As expected, most activity was found in the exclusion peak but $17 \%$ occurred outside this region, between KAV 1.0 and 2.0, giving MW limits of 500-280, as calculated from the standard curve (fig. 1c). A line of closest fit drawn through the histogram in fig. 5 would give a MW of 380 , but this does not coincide with any peak of ultra-violet absorbence; the nearest one would be at KAV 1.65, giving a MW of 333. 


\section{Discussion}

The results from ultrafiltration suggest that enterotoxins occurred in four MW classes. If mean results are taken, supernates from cultures of strain P16 appear to have contained about $17 \%$ of toxin with $\mathrm{MW}>105,27 \%$ with MW $3 \times 10^{4}-10^{4}, 10 \%$ with MW $10^{4}-10^{4}$ and $46 \%$ with $\mathrm{MW}<10^{4}$. However, it seems likely that some of the higher-MW toxins fragmented to yield units of $M W<10^{4}$; the results from G50 Sephadex-gel filtration (fig. 4) suggest that the fraction which broke down was the toxin of MW $6.7 \times 10^{4}$.

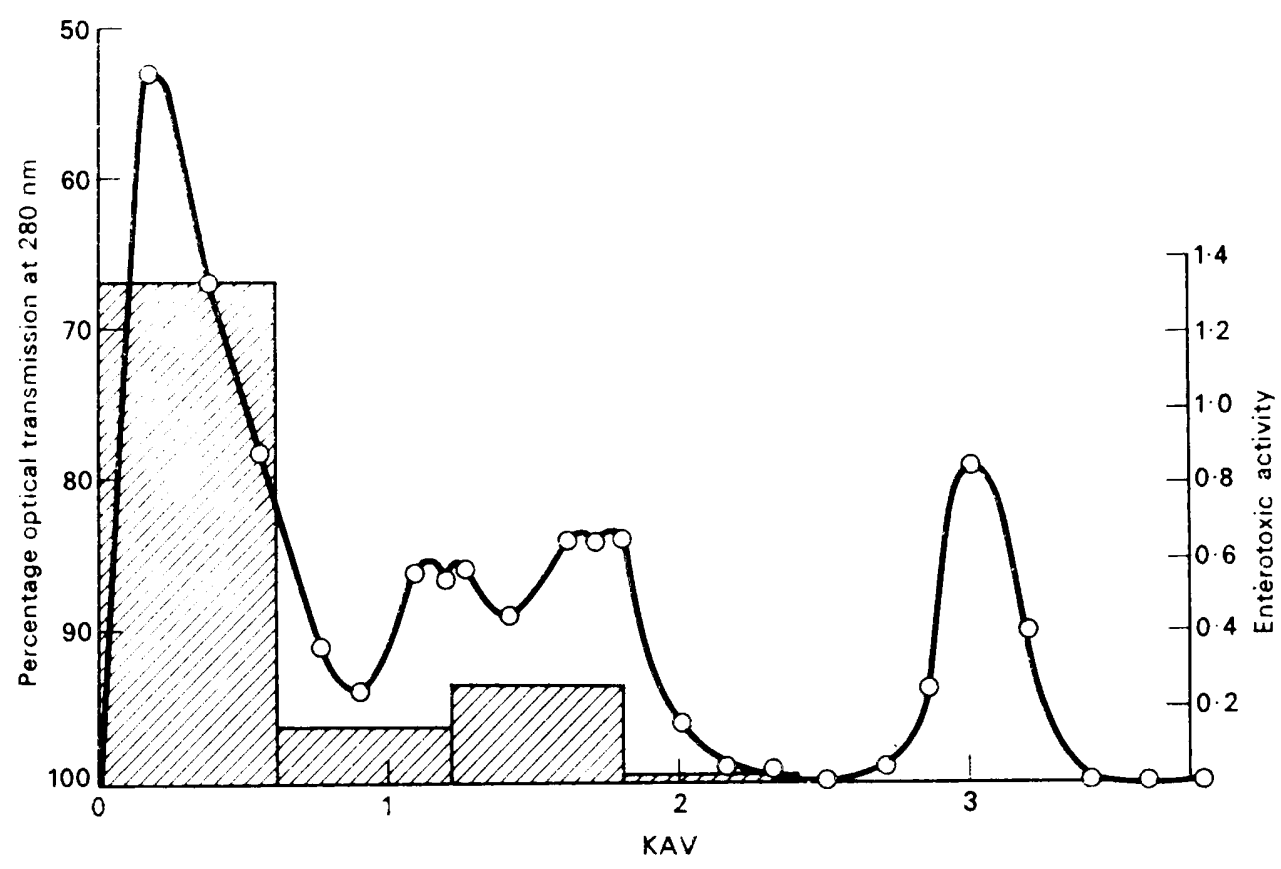

FIG. 5.-Separation of low-MW enterotoxin on Sephadex G10. The column measured $38 \times 2.5 \mathrm{~cm}$ and the eluant was phosphate buffer. The toxin consisted of $10 \mathrm{ml}$ of a 20 -fold concentrate prepared by freeze-drying. Symbols as in fig. 3.

When freeze-dried concentrates were used in gel filtrations, $17 \%$ of the total enterotoxic activity was recovered between KAV 0.2 and 0.7 on Sepharose 4B, $60 \%$ between KAV 0.3 and 0.8 on Sephadex G50 and $17 \%$ between KAV 1 and 2 on Sephadex G10. These results thus accounted for $94 \%$ of the total activity in freeze-dried concentrates and probably included all the major enterotoxic components in culture supernates of strain P16.

In general, the results from gel filtration and ultrafiltration agreed well. Both the Sepharose 4B and XM.100 filtrations indicated that about $17 \%$ of the total enterotoxic activity had a MW exceeding $10^{5}$. The Sephadex G50- and PM.10-filtration data both suggested that there were two toxins with a MW between $3 \times 10^{4}$ and $10^{4}$, but it must be assumed that the toxin having a MW of $9.5 \times 10^{3}$ did not pass through the PM.10 membrane, perhaps because of some steric factor. The UM.2 filtration data (table I) indicated a MW of $<10^{3}$ for 
$46 \%$ of the total activity and a MW within the range $10^{3}-3 \times 10^{4}$ for $38 \%$. The Sephadex G10 and G50 data suggested, on the other hand, corresponding percentage values of 17 and 60 . This discrepancy may have resulted from the fragmentation which, as has already been explained, probably affected the toxin of MW $6.7 \times 10^{3}$ during ultrafiltration; if so, it is probable that the gel-filtration results reflected more accurately the original composition of enterotoxic supernates than did the ultrafiltration figures. Reassessing the UM.2 and PM.10filtration data in the light of this observation, we suggest that $27 \%$ of the total activity represented stable toxin of MW $9.5 \times 10^{3}, 33 \%$ represented unstable toxin of MW $6.7 \times 10^{3}$ and $17 \%$ represented toxin of $\mathrm{MW}<10^{3}$.

To summarise our results with reference to those of other laboratories, we found that a strain of $E$. coli (serotype $09 ; \mathrm{K} 9$ ) produced enterotoxins having MW values consistent with those found by others. Some investigators (Larivière, 1971; Jacks et al., 1973) have suggested that most enterotoxic activity is associated with a MW of about $10^{6}$, whilst others (Kohler, 1968, 1971b; Smith and Gyles, 1970a) have stated that only low-MW toxin is found in culture supernates; Kohler (1971b) has presented data that suggest that the MW is just below that of sucrose. Bywater (1972), using a pathogenic strain of $E$. coli from a calf, suggested that there was no high-MW toxin but that most of the activity was associated with MW values within the range $10^{4}-10^{3}$, and only a little with values of $<10^{3}$. However, his results showed some increase in activity in the PM.10 retentate which might have been caused by high-MW toxin; furthermore, some high-MW activity might have been lost during precipitation by acetone, a solvent which in our experience (unpublished observation) has resulted in poor recovery of activity. The high-MW toxin produced in our studies had a MW slightly lower than that found by Larivière (1971) and Jacks et al. (1973) whilst our low-MW toxin was very similar to that found by Kohler (1971), especially if the weight of 333 suggested by ultraviolet absorbence was correct. Likewise our medium-MW toxins had weights within the range stated by Bywater (1972), viz., 104-103. One of our toxins had a MW of $9.5 \times 10^{3}$ yet would not pass a PM.10 membrane, but it should be pointed out that the MW was only just below that excluded by this type of filter.

Thus it appears that the differences between our results and those of others are quantitative rather than qualitative and might well be related to the use of different strains of bacteria and of different methods of culture and preparation. We have noted (unpublished observation) that prolonged incubation of cultures increases the proportion of low-MW toxin and that another strain of E. coli, serotype $0141 ; \mathrm{K} 85 a b ; \mathrm{K} 88 a b ; \mathrm{H} 4$, seems to produce neglible amounts of high-MW toxin. This agrees well with other observations on strain variability (Truszcynski and Ciosek, 1972). One of the toxins with a MW in the medium range apparently fragmented during ultrafiltration whilst the other remained stable, indicating that their molecular structures may have been quite different and that the interrelationship of enterotoxins may not be quite as simple as suggested by Smith and Gyles (1970a); moreover, it would seem that, in molecular terms, $E$. coli enterotoxin may not be directly comparable with Vibrio cholerae toxin (Finkelstein, Peterson and Lospalluto, 1971; Lospalluto and 
Finkelstein, 1972). The MW of the low-MW toxin is very close to that of cyclic 3',5'-adenosine monophosphate (c-AMP; MW 347) which has been implicated in E. coli enteritis (Al-Awqati et al., 1972). This coupled with the probable fragmentation of one of the medium-MW toxins to give low-MW toxin leads to the speculation that a polymer might be capable of breaking down to yield mono-nucleotides that interfere with a system normally regulated by c-AMP.

\section{SUMMARY}

Enterotoxin was produced by growing Escherichia coli strain P16 (serotype O9; K9) in a defined medium. Ultrafiltration and gel-filtration studies suggested that toxic activity was produced by enterotoxins, $17,27,33$ and $17 \%$ of which had, respectively, MW values of $5.9 \times 10^{5}, 9 \cdot 5 \times 10^{3}, 6.7 \times 10^{3}$ and 380 . Inactivation accounted for the remaining $6 \%$. There was some evidence that toxin of MW 6.7 $\times 10^{3}$ fragmented to produce toxin of MW 380 .

We thank Mrs H. Steels, Mrs K. Martin and Mr M. Everett for their expert technical assistance.

\section{REFERENCES}

Al-Awqati, Q., Wallace, C. K. and Greenough, W. B. 1972. Stimulation of intestinal secretion in vitro by culture filtrates of Escherichia coli. J. infect. Dis., 125, 300.

BYWATER, R. J. 1972. Dialysis and ultrafiltration of a heat-stable enterotoxin from Escherichia coli. J. med. Microbiol., 5, 337.

DE, S. N. AND ChatterJe, D. N. 1953. An experimental study on the mechanism of action of Vibrio cholerae on the intestinal mucous membrane. J. Path. Bact., 66, 559.

Evans, D. J., Chen, L. C., Curlin, G. T. and Evans, D. G. 1972. Stimulation of adenyl cyclase by Escherichia coli enterotoxin. Nature (Lond.), New Biol., 236, 137.

Finkelstein, R. A., Peterson, J. W. And Lospalluto. J. J. 1971 . Conversion of cholera exo-enterotoxin (choleragen) to natural toxoid (choleragenoid). J. Immun., 106, 868.

Jacks, T. M., Wu, B. J., Braemer, A. C. ANd Bidlack, D. E. 1973. Properties of the enterotoxic component in Escherichia coli enteropathogenic for swine. Infect. Immun., 7, 178.

KoHLER, E. M. 1968. Enterotoxic activity of filtrates of Escherichia coli in young pigs. Am. J. vet. Res., 29, 2263.

KOHLER, E. M. 1971a. Enterotoxic activity of whole cell lysates of Escherichia coli in young pigs. Am. J. vet. Res., 32, 731.

KoHLER, E. M. 1971b. Observations on enterotoxins produced by enteropathogenic Escherichia coli. Ann. N.Y. Acad. Sci., 176, 212.

KoHLER, E. M. AND Cross, R. F. 1971. Feeding bacteria-free whole cell lysates of Escherichia coli to gnotobiotic pigs and the effects of giving antiserums. Am. J. vet. Res., 32, 739.

LARIVIÈRE, S. 1971. Physical and biological characterisation of Escherichia coli enterotoxin. Ph.D. Thesis. University of Guelph, Canada.

Lospalluto, J. J. AND Finkelstein, R. A. 1972. Chemical and physical properties of cholera exo-enterotoxin (choleragen) and its spontaneously formed toxoid (choleragenoid). Biochim. biophys. Acta, 257, 158.

Mitchell, I. DE G., TAME, M. J. AND Kenworthy, R. 1974. Conditions for the production of Escherchia coli enterotoxin on a defined medium. J. med. Microbiol., 7, 395.

Moon, H. W., Sorensen, D. K. AND SAUtTER, J. H., 1966. Escherichia coli infection of the ligated intestinal loop of the newborn pig. Am.J. vet. Res., 27, 1317.

SMITH, H. W. AND GyLES, C. L. 1970a. The relationship between two apparently different enterotoxins produced by enteropathogenic strains of Escherichia coli of porcine origin. J. med. Microbiol., 3, 387. 
SMITH, H. W. AND GyLES, C. L. $1970 b$. The effect of cell free fluids prepared from cultures of human and animal enteropathogenic strains of Escherichia coli on ligated intestinal segments of rabbits and pigs. J. med. Microbiol., 3, 403.

TruszCZYNSKI, M. AND CIOSEK, D. 1972. The influence of the contents of different K antigens and of physical factors on the toxicity of enterotoxins and water extracts of Escherichia coli. Res. vet. Sci., 13, 212. 